\title{
The effect of educational intervention based on health belief on improvement of metabolic indices of patients with diabetes type II living in rural areas
}

\section{Ebrahim Falahati}

Kermanshah University of Medical Sciences

Alireza Abdi (D A_abdi61@yahoo.com )

Kermanshah University of Medical Sciences

Hossein Ashterian

Kermanshah University of Medical Sciences

Nader Salari

Kermanshah University of Medical Sciences

\section{Farzad Momenfar}

Kermanshah University of Medical Sciences

Research article

Keywords: Diabetes Type II, Health Belief Model, Educational Intervention, Metabolic Indices

Posted Date: August 19th, 2019

DOI: https://doi.org/10.21203/rs.2.13093/v1

License: (9) This work is licensed under a Creative Commons Attribution 4.0 International License.

Read Full License 


\section{Abstract}

Background: Nowadays, diabetes is one of the most common health problems worldwide that may cause severe side effects on the circulatory system, nervous system, kidneys, eyes, and feet. Health care education makes patients involved in caring and it is one of the main measures to attenuate the load of the disease on health system. The present study is an attempt to survey the effect of health belief-based educational intervention on improvement of metabolic indices in patients with diabetes type II in rural areas of Kermanshah-Iran. Methods: The study was carried out as a clinical trial in 2018 on 48 individuals grouped into intervention and control groups (each with 24 members) randomely. The participants were patients with diabetes type II visiting rural comprehensive services centers of PaveKermanshah-Iran. They were selected randomly so that visitors to Shamshir Village clinic of were selected as the intervention group and the patients in Serias and Darebaian villages' centers were selected as the control group. Data gathering was done using demographics questionnaire and a metabolic indices checklist before and three months after the educational intervention. The participants in the intervention group were grouped into two groups of 12-15 members and the intervention was conducted based on health belief model in six sessions each for 60 minutes. Data analyses were done using SPSS (v.24) and descriptive statistics and Squared Chi test, Wilcoxon test, Mann Whitney test, independent t-test, and paired t-test. Findings: Before the intervention, there was no significant difference between the two groups in terms of demographics and diabetes metabolic indices $(P>0.05)$. However, after the intervention, there was a significant difference between the two groups in terms of glycated hemoglobin $(p=0.038)$ and fasting blood glucose level $(P=0.006)$. The difference between the two groups was not significant in terms of BMI $(p=0.301)$, cholesterol level $(p=0.797)$, triglyceride $(p=0.439)$, lipoprotein with low density $(p=0.157)$, and lipoprotein with high density $(p=0.664)$. Conclusion: The results showed that health belief-based educational intervention was effective in decreasing blood glucose level in diabetic patients. It is recommended using this approach as a part of therapeutic intervention and disease control in diabetic patients.

\section{Background}

Prevalence of diabetes is growing due to rapid population growth, increase of life expectancy, growth of urbanism, low physical activity, and increase in prevalence of obesity [1]. According to the International Federation of Diabetes, while the diabetic patients population in 2000 was less than 200 million, this figure reached 451 million (age range: 18-99 years) in 2017, and it is expected to hit 693 million in 2045. It is notable that about one half of diabetic patients are not diagnosed [2]. Prevalence of diabetes in the Middle East is growing fast and it is estimated that by 2030 Iran, after Pakistan, will have the second highest growth rate of diabetes prevalence. In 2008, the population of diabetic patients was four million and this figure is estimated to be 12 million by 2022 [3-5].

Experts of health sciences believe that diabetic patients need to undertake the responsibility of many of their care behaviors such as following the recommended diet, exercising, regular physical activity, following drug usage prescription, monitoring blood glucose level, inspecting feet, and visiting physician 
on a regular basis [6, 7]. Results of studies in Germany and the UK have revealed that about $50-60 \%$ of diabetic patients demonstrated an increase in the level of glycated hemoglobin ( $\mathrm{HbA} 1 \mathrm{c})$ despite receiving therapeutic services [8-10]. Although no definite treatment has been found for diabetes, proper health cares are effective in controlling the symptoms and disabling side effects so that the first objective in diabetes treatment protocols is to control blood glucose level. In this regard, $\mathrm{HbAlC}$ is the best indicator of diabetes control so that it is considered as a golden standard. The index represents mean blood glucose level over the past two to three months so that it has a close relationship with emergence of chronic sideeffects of diabetes like microvascular in particular. One percent decrease in HbAlC in 10 years results in $21 \%$ decrease in diabetes caused deaths and $40 \%$ decrease in the eyes, renal, and neural side-effect (11, 12).

Diabetes and diabetes type II in particular creates lipid metabolic disorders and an increase in the plasma fatty acids level is a key factor in development of insulin resistance. Increase in plasma fatty acids causes dyslipidemia in diabetic patients in the form of increase in low density lipoprotein (LDL), and decrease of high density lipoprotein (HDL). This iatrogenic function of lipoproteins (increase of triglyceride, increase of $\mathrm{LDL}$, and decrease of $\mathrm{HDL}$ ) causes atherosclerosis and increases the risk of cardiovascular incidents, which is the main cause of death among patients with diabetes type II [13].

Taking into account that the majority of health problems have to do with the individual's behavior, behavioral theories and patterns can be used to facilitate recognizing and perceiving the factors effective in one's behavior and determine how these factors function [14]. Health belief model is one of the educational models that illustrates the relationship between health beliefs and health behaviors so that it emphasizes on individual's motivation to perform tasks [15]. The basic ideas of health belief were introduced by Hochbaum et al. in the 1950s. The reason for using this model was public's reluctance to accept health concerns; so that the model tries to elaborate on why people find themselves beyond the risk of illnesses. The constructs of health belief model include perceived susceptibility, perceived severity, perceived benefits, perceived barriers, cues to action, and self-efficiency $[15,16]$. Different studies have surveyed the effectiveness of educational intervention based on health belief model on improvement of caring behaviors in the patient and improvement of metabolic control in diabetic patient. Mohammadi et al. (2018) and Pourgholani et al. (2017) highlighted the positive effect of educational intervention on attenuation of $\mathrm{HbA} 1 \mathrm{C}$ [17-18]. Although the effect of nutrition, exercising, and medication on diabetes have been subject of several studies, there is a paucity of studies on the simultaneous effects of educations on nutrition, exercising, and medication in diabetes type II. Taking into account that the majority of studies have only focused on one of the standards of diabetes control and have rarely dealt with metabolic indices of diabetes, so the present study is an attempt to determine the effect of educational intervention based on health belief model on metabolic indices of patients with diabetes type II in rural areas of Iran.

\section{Methods}


Before the educational intervention, the participants signed an informed written consent. Afterwards, demographics information form was filled out followed by the required tests. The educational intervention was done as six weekly sessions (60mins) by the authors at the health centers following a well-codified plan based on the constructs of the health belief model. Throughout the course, the patients were invited to take part in the educational program. The educational program included lecturing, answering questions, group discussion, brain storming, demonstration, and handing over an educational pamphlet. The sessions were held in groups of 12-15 participants to ensure enough time for involving patients in discussions and answering questions. Giving lecture was the best way to save time and cost and groups discussion was the best way to involve the patients in the learning process and ensure deep understanding of the topics. It is notable that the educational contents were designed based on the educational objectives of the national program of preventing and controlling diabetes published by the ministry of health for health personnel, the atlas of the American Diabetes Association, and Harrison's Principles of Internal Medicine. To facilitate understandability of the materials for the diabetic patients and avoid misunderstanding and along with answer questions and group discussion to review the materials, the last session was dedicated to train one of the active members of the families and they received a pamphlet designed by the authors. The educational intervention was conducted at three stages and in six sessions.

Stage one consisted of one session and designed to raise the participants' awareness about the sideeffects of diabetes and improve participants' perception about the pathological extent of the diabetes side effects. Topics covered at this stage were an introduction to the nature of diabetes and the side effects, definition of diabetes control, and elaboration on the necessity of monitoring blood sugar level. Stage two included three sessions and designed to improve perception of the subjects about the benefits and obstacles of following a diabetic diet, medical orders, and having physical activity. Topics like importance of observing diet, limitations with regard to food stuff, definition of following drug regimen and its effects, and importance of physical activity in managing diabetes. Afterward, the solutions to overcome each one of the obstacles were discussed in group and along with elaborating on healthy behaviors, the subjects were ensured that following such behaviors not only is economic in terms of money and time, but also the expenses are not comparable with the costs of treating the diabetes sideeffects. Moreover, wrong beliefs and probable misunderstandings were solved throughout group discussions. Stage three consisted on two sessions and designed to facilitate and incentivize healthy behaviors and improve self-efficiency in the patients. Session one was dedicated to improving selfefficacy of patients so that a successful diabetic patients, as a role model, was invited to share their experiences and improve the patient's belief in their abilities. Session two was aimed at facilitating and incentivizing carrying out the behaviors. One of the family members was also present in this session to act as a motivator in the days after the intervention. Throughout this, the control group only received the routine activities of the health centers (trainings by physician and health assistance) (Table1).

To determine effectiveness of the medical intervention, the subjects were examined three months after the intervention. Results of the tests three months of the intervention were analyzed in SPSS24 using descriptive and inferential statistics. Frequency and frequency percentage were calculated for nominal 
and ordinal variables and mean and standard deviation were calculated for the quantitative variables. Moreover, normal distribution of the data was examined using Shapiro-wilk test. Paired t-test or Wilcoxon tests were used to compare the indices before and after the intervention and independent t-test or Mann Whitney tests were used to compare the indices between the two groups before and after the intervention. Moreover, Squared Chi test was used to compare the two groups in terms of nominal and ordinal variables. In the case of inferential statistics, p-value was less than 0.05 .

\section{Results}

In this study fifty diabetic patients were enrolled. After the educational intervention, one participant from the intervention group and one from the control group were excluded because of failing to give the tests. Therefore, the study was conducted on 48 participants (24 in intervention group and 24 in control group). There was no significant difference between the control and intervention groups in terms of personal specifications like age, gender, marital status, education, job, and term of the disease - i.e. the two groups were homogenous (Table 2). Mean age of the participants in the intervention and control groups was $55.2 \pm 1.23$ and $57.66 \pm 1.09$ years respectively (table 3 ). Moreover, $62.5 \%$ of the participants were women $(n=30)$ and $37.5 \%$ were men $(n=18)$. The majority in the both groups were married $(85.4 \%)$ and the rest were widows/widowers. In terms of education level, $54.2 \%$ were literate and $45.8 \%$ were illiterate and the majority were unemployed (58.3\%) and $41.7 \%$ were employed. Additionally, $79.2 \%$ of the patients had less than five children.

Table 4 lists the results of Shapiro-Wilk test to determine normal distribution of the variables based on the study groups so that variables with test score higher than 0.05 have normal distribution and non-normal distribution otherwise (Table 4).

Before the intervention, there was no significant difference between the two groups in terms of BMI $(p=0.578), \operatorname{FBS}(p=0.765), \mathrm{HbAlc}(p=0.496), \mathrm{CHOL}(p=0.263)$, triglyceride $(p=0.244), \mathrm{HDL}(p=0.833)$, and LDL $(p=0.109)$. Based on Mann Whitney test and independent $t$-test there was a significant difference between the two groups after the intervention in terms of HbAlc $(P=0.038)$ and FBS $(p=0.006)$. According to Wilcoxon test, there was a significant difference in the intervention group before and after the intervention in terms of ordinal mean score of HbAlc and FBS. No such difference was observed in the contn the intervention and control groups in terms of $\mathrm{BMI}(p=0.301), \mathrm{CHOL}(p=0.797)$, triglyceride $(p=0.439), H D L(p=0.664)$, and LDL ( $p=0.157)$. However, the mean scores of BMI, CHOL, and LDL decreased in the intervention groups after the intervention; although, the difference was not significant (Table 5 and 6).

\section{Discussion}

In this study, the effects of health belief-based educational intervention on improvement of the metabolic indices of patients with diabetes type II were examined. Mean score of HbA1c was higher than normal level in the control and experiment groups before and after the intervention. This indicates negligence of 
blood sugar control by the patients, which increases the risk and severity of diabetes side effects in future. There was a significant decrease in the mean score of $\mathrm{HbA} 1 \mathrm{c}$ of the participants in the intervention group after the educational intervention. While, the trivial decrease on $\mathrm{HbA} 1 \mathrm{c}$ in the control group after the intervention was not significant. Mohammadi et al. (2018) reported similar results after six months educational intervention based on health belief model [17]. Moreover, the results are consistent with Pourgholami et al. (2017), Nadine Kuniss et al. (2018), and Jiang et al. (2018) [18-20]. The findings can be considered as indicators of effectiveness of the educational strategy. Although, it is a progressive and chronic disease, diabetes can be controlled by following caring behaviors by the patients and achieve preferred results. However, the common point of the study with other studies is that the effects of nutritional education, exercising, and medication were measured at the same time so that psychological intervention was also taken into account occasionally. The positive effects of combined effects of the intervention may lead to a new and different approach to optimize the conventional interventions for diabetic patients. A meta-analysis study by Esmaiel et al. showed that using psychological treatment to control $\mathrm{HbA} 1 \mathrm{c}$ is effective in long-run [21]. Taking into account the living condition in village and limited access to medical and health services, improvement of self-care behaviors is of great importance. The health belief model is an individual-centered educational model and mainly emphasizes on motivational factors and self-efficiency of the patient. Inconsistent with our results, Matlabi et al. (2016) and Raiesi et al. (2017) found the difference in mean score of HbA1c three months after the educational intervention insignificant $[12,22]$.

There was no significant difference between mean FBS scores of the intervention and control group before the intervention. After the intervention, FBS score in the intervention group decreased, which indicates the positive effect of the intervention on the subjects. The findings is consistent with other studies like Davar et al. (2017), Zarban et al. (2013), Shamsi et al. (2009) [23-25]. However, the findings are inconsistent with Matlabi et al. (2016) who found the changes in FBS after the intervention insignificant [22].

Many studies on diabetic patients omit serum lipid level and only focus on HbA1c and FBS, which is not the case in this study. This a notable point since high FBS and serum lipids may intensifies diabetic side effects. Miller et al. (2002) studied 98 elderly patients with diabetes type II. Despite improvements in glycemic control, the difference between the serum lipids was not significant [26]. Although the intervention groups demonstrated better clinical response in terms of mean score of lipid profile, consistent with Miller et al. [26] the changes were not significant. The reason for insignificant difference in Miller's study was the short time period available for the participants to make change in their diet or in their dietary fat consumption pattern, which is consistent with the present study. Lack of significant change in the present study might be due to lack of supervision and control on patients' daily activities and probable variations in the type of food used by the subjects.

The findings highlight the need for more attention to lipid profile in diabetic patients and patients with diabetes type II in particular. The officials of health services are required to pay special attention to control blood lipids in diabetic patients. Kessler et al. (2012) reported that at least eight weeks of practice 
is needed to enable the patient of controlling HDL so that studies with less than eight weeks intervention period fail to achieve significant changes in lipid profile [27]. In this regard, our results are not consistent with Doostan et al. (2016) and Li Suging et al. $(2017)[29,30]$. The results indicated that educating patients and implementing clinical feeding techniques were effective in attenuating the side effects, mortality rate, and challenges (i.e. expenses) in diabetic patients. Knowing that patients have a major role to play in caring, provision of educational services to them is essential [26]. Although, following special diets is a serious challenge in the way of controlling diabetes for both the patient and physician, it is a key factor in controlling diabetes. The majority of the patients find it difficult to adhere diabetic special diet or change their life study as personal and cultural nutrition preferences influence their performance [31].

\section{Conclusions}

The results supported the positive effect of educational intervention based on health belief model on attenuation and improvement of glycemic indices of patients with diabetes type II. There were changes in lipid profile of the patients; however, the changes were not significant. Using the model as a caring measure in clinics is recommended.

\section{Abbreviations}

HBM: health belief model

\section{Declarations}

\section{Ethics approval and consent to participate}

The study was approved by research ethics committee of Kermanshah University of medical sciences, Kermanshah-Iran with ethics number: IR.KUMS.REC.1396.387 by date of 25-10-2017, also the informed consent was taken from the subjects, and they assured about confidentiality and anonymity of the personal information, these measures were done in accordance with the Helsinki Declaration.

\section{Consent for publication}

All the authors consented to publish the study in your journal

\section{Availability of data and material}

Data available by contacting the corresponding author

\section{Competing interests}

The authors declare there are no competing interests 


\section{Funding}

The study was funded by Kermanshah University of Medical Sciences with number 96539

\section{Authors' contributions}

$E F, A A, N S$, and HA contributed in designing the study, EF and HA collected the data, and analyzed by AA and NS, the final report and article were written by EF, FM, and AA, and the paper were read and approved by all the authors

\section{Acknowledgement}

This article is part of an MSc dissertation in internal-surgery nursing and a report of a part of research plan approved in Kermanshah University of Medical Sciences and Medical No.96539 the Ethics Committee (IR.KUMS.REC.1396.387) of Kermanshah University of Medical Sciences as well as Iranian registry of clinical trial with no. IRCT20170619034641N2. The authors wish to thank the officials of Research deputy and School of Nursing and Midwifery of Kermanshah University of medical sciences, and health center of Pave City, and the patients for their cooperation.

\section{References}

1. Yang W, Lu J, Weng J, Jia W, Ji L, Xiao J, et al. Prevalence of diabetes among men and women in China. New England Journal of Medicine. 2010;362(12):1090-101.

2. Cho N, Shaw J, Karuranga S, Huang Y, da Rocha Fernandes J, Ohlrogge A, et al. IDF Diabetes Atlas: Global estimates of diabetes prevalence for 2017 and projections for 2045. Diabetes research and clinical practice. 2018;138:271-81.

3. Shaw JE, Sicree RA, Zimmet PZ. Global estimates of the prevalence of diabetes for 2010 and 2030. Diabetes research and clinical practice. 2010;87(1):4-14.

4. FarhadMolashahi L, Kadeh H, Saravani S, Dashipoor A. Level of Glycemic Control in Diabetic Patients Reffering to Zahedan Dental School (Iran) in 2005. Journal of Mashhad Dental School. 2011;3:195-204.

5. Rajab A. The effect of self care program education through group discussion method on knowledge and practice in diabetic adolescent girls referring to Iranian Diabetes Society. Iranian Journal of Medical Education. 2011;10(5):982-93.

6. Gatt S, Sammut R. An exploratory study of predictors of self-care behaviour in persons with type 2 diabetes. International journal of nursing studies. 2008;45(10):1525-33.

7. Yamaguchi Y, Miura S, Urata H, Himeshima Y, Yamatsu K, Otsuka N, et al. The effectiveness of a multicomponent program for nutrition and physical activity change in clinical setting: Short-term effects of PACE+ Japan. International Journal of Sport and Health Science. 2003;1(2):229-37.

8. Gough S, Frandsen K, Toft A. Failure of insulin monotherapy in patients with type 2 diabetes. Diabetic Medicine. 2006;23:551. 
9. Grant RW, Buse JB, Meigs JB. Quality of diabetes care in US academic medical centers. Diabetes care. 2005;28(2):337-442.

10. Guler S, Vaz JA, Ligthelm R. Intensification lessons with modern premixes: from clinical trial to clinical practice. diabetes research and clinical practice. 2008;81:S23-S30.

11. Evans G, Kantrowitz E. Strategies for reducing morbidity and mortality from diabetes through healthcare system interventions and diabetes self-management education in community settings. Morbidity and Mortality Weekly Report Recommendations and Reports. 2001;50:1-15.

12. Reisi M, Mostafavi F, Javadzade H, Jalilian F, Mahaki B, Sharifirad G. Effect of theory based education on blood sugar control in type-2 diabetic patients. Iranian Journal of Endocrinology and Metabolism. 2017;18(6):420-31.

13. Cederberg H, Laakso M. Type 2 diabetes mellitus and dyslipidemia. Dyslipidemias: Springer; 2015. p. 99-113.

14. Karimy M, Abedi A, Amin-Shokravi F, Tavafian SS. Preventing HIV Transmission among the OpiateDependent Population in Zarandieh: Evaluation of the HBM-Based Educational Programs. Health Education \& Health Promotion. 2013;1(1):21-31.

15. Glanz K, Rimer BK, Viswanath K. Health behavior and health education: theory, research, and practice: John Wiley \& Sons; 2008.

16. Sharma M, Romas JA. Theoretical foundations of health education and health promotion: Jones \& Bartlett Publishers; 2011.

17. Mohammadi S, Karim NA, Talib RA, Amani R. The impact of self-efficacy education based on the health belief model in Iranian patients with type 2 diabetes: a randomised controlled intervention study. Asia Pacific journal of clinical nutrition. 2018;27(3):546-55.

18. Porgholmi M, Farmanbar R, Kasmaei P, Omidi S. The Effect of Training Program Based on Health Belief Model Developed by the Fear of Self-Care Behavior and Hba1c Levels in Patients with Type 2 Diabetes. Iranian Journal of Health Education and Health Promotion. 2017;5(1):65-72.

19. Kuniss N, Müller UA, Kloos C, Müller R, Starrach G, Jörgens V, et al. Substantial improvement in $\mathrm{HbA} 1 \mathrm{c}$ following a treatment and teaching programme for people with type 2 diabetes on conventional insulin therapy in an in-and outpatient setting. Acta diabetologica. 2018;55(2).

20. Jiang X, Fan X, Wu R, Geng F, Hu C. The effect of care intervention for obese patients with type II diabetes. Medicine. 2017;96(42).

21. Ismail K, Winkley K, Rabe-Hesketh S. Systematic review and meta-analysis of randomised controlled trials of psychological interventions to improve glycaemic control in patients with type 2 diabetes. The Lancet. 2004;363(9421):1589-97.

22. Motallebi F, Shakerian S, Ranjbar R. Effect of 8 weeks aerobic interval training on glycosylated hemoglobin and insulin resistance index in diabetic mellitus Type 2 women. The Horizon of Medical Sciences. 2016;22(2):137-43.

23. Dadvar N, Ghalavand A, Zakerkish M, Hojat S, Alijani E. The Effect of Aerobic Training and Urtica Dioica on Lipid Profile and Fasting Blood Glucose in Middle Age Female with Type II Diabetes. 
Jundishapur Sci Med J. 2017;15(6):507-16.

24. Zareban I, Niknami S, Hidarnia A, Rakhshani F, Karimy M, Shamsi M. The effect of education program based on health belief model on decreasing blood sugar levels in diabetic type 2 patients in Zahedan. Health Scope. 2013;2(2):73-8.

25. Shamsi M, Sharifirad G, Kachoyee A, Hassanzadeh A. The effect of educational program walking based on health belief model on control sugar in woman by type 2 diabetics. Iranian Journal of Endocrinology and Metabolism. 2009;11(5):490-9.

26. Miller CK, Edwards L, Kissling G, Sanville L. Nutrition education improves metabolic outcomes among older adults with diabetes mellitus: results from a randomized controlled trial. Preventive medicine. 2002;34(2):252-9.

27. Kessler HS, Sisson SB, Short KR. The potential for high-intensity interval training to reduce cardiometabolic disease risk. Sports medicine. 2012;42(6):489-509.

28. Afshoun Pour MT, Habibi A, Ranjbar R. The Impact of Circuit Resistance Exercise Training on Metabolic Parameters in Type 2 Diabetics Men. Scientific Medical Journal. 2016;15(2):125-38.

29. Doostan F, Lashkari T. The Effect of Clinical Nutrition Education on Blood Glucose and Serum Lipids Control: A Study on Type II Diabetic Patients Referred to Diabetes Center of ShahidBahonar Hospital, Kerman, Iran. Journal of Health and Development. 2016;5(1):79-89.

30. Li S, Roschkov S, Alkhodair A, O'Neill BJ, Chik CL, Tsuyuki RT, et al. The Effect of Nurse PractitionerLed Intervention in Diabetes Care for Patients Admitted to Cardiology Services. Canadian journal of diabetes. 2017;41(1):10-6.

31. Zipp C, Roehr JT, Weiss LB, Filipetto F. Impact of intensive nutritional education with carbohydrate counting on diabetes control in type 2 diabetic patients. Patient preference and adherence. 2011;5:712.

\section{Tables}

Table 1: the stage/ sessions of the intervention 


\begin{tabular}{|l|l|l|}
\hline & Objective & Topics \\
\hline $\begin{array}{l}\text { Stage } \\
\text { one (one } \\
\text { session) }\end{array}$ & $\begin{array}{l}\text { To raise the participants' awareness about } \\
\text { the side-effects of diabetes and improve } \\
\text { participants perception about the } \\
\text { pathological extent of diabetes side effects. }\end{array}$ & $\begin{array}{l}\text { Introduction to the nature of diabetes and the } \\
\text { side effects, definition of diabetes control and } \\
\text { elaboration on the necessity of monitoring blood } \\
\text { sugar level. }\end{array}$ \\
\hline $\begin{array}{l}\text { Stage } \\
\text { two } \\
\text { (three } \\
\text { sessions) }\end{array}$ & $\begin{array}{l}\text { To improve perception of the subjects about } \\
\text { the benefits and obstacles of following a a } \\
\text { diabetic diet, medical orders, and having }\end{array}$ & $\begin{array}{l}\text { Importance of observing diet, limitations with } \\
\text { regard to food stuff, definition of following drug } \\
\text { regimen and its effects, and importance of } \\
\text { physical activity in managing diabetes. }\end{array}$ \\
\hline $\begin{array}{l}\text { Stage } \\
\text { three } \\
\text { (two } \\
\text { sessions) }\end{array}$ & $\begin{array}{l}\text { To facilitate and incentivize healthy behaviors } \\
\text { and improve self-efficiency in the patients }\end{array}$ & $\begin{array}{l}\text { A successful diabetic patients, as a role model, } \\
\text { was invited to share their experiences. Involving } \\
\text { one of active family members in the education } \\
\text { process }\end{array}$ \\
\hline
\end{tabular}

Table 2: comparing the demographic characteristics of the participants in two groups

\begin{tabular}{|c|c|c|c|c|c|c|c|c|c|}
\hline & \multirow{2}{*}{\multicolumn{2}{|c|}{$\begin{array}{l}\text { Group } \\
\text { Variable }\end{array}$}} & \multicolumn{2}{|c|}{ Intervention } & \multicolumn{2}{|c|}{ Control } & \multirow[t]{2}{*}{$\mathrm{N}$} & \multirow[t]{2}{*}{$\%$} & \multirow[t]{2}{*}{ Sig. } \\
\hline & & & $\mathrm{N}$ & $\%$ & $\mathrm{~N}$ & $\%$ & & & \\
\hline \multirow[t]{2}{*}{1} & \multirow[t]{2}{*}{ Gender** } & M & 9 & 37.5 & 9 & 37.5 & 18 & 37.5 & \multirow[t]{2}{*}{$X^{2}=0.0001$} \\
\hline & & $\mathrm{F}$ & 15 & 62.5 & 15 & 62.5 & 30 & 62.5 & \\
\hline \multirow[t]{2}{*}{2} & \multirow[t]{2}{*}{ Marital status* } & Widow & 4 & 16.7 & 3 & 12.5 & 7 & 14.6 & $X^{2}=0$ \\
\hline & & Married & 20 & 83.3 & 21 & 87.5 & 41 & 85.4 & $P=0.500$ \\
\hline \multirow[t]{2}{*}{3} & \multirow[t]{2}{*}{ Education** } & Illiterate & 12 & 50 & 10 & 41.7 & 22 & 45.8 & $\mathrm{X}^{2}=0.336$ \\
\hline & & Literate & 12 & 50 & 14 & 58.3 & 26 & 54.2 & $\mathrm{P}=0.386$ \\
\hline \multirow[t]{2}{*}{4} & \multirow[t]{2}{*}{ Employment** } & Employed & 11 & 54.2 & 9 & 37.5 & 20 & 41.7 & $\mathrm{X}^{2}=0.343$ \\
\hline & & Unemployed & 13 & 45.8 & 15 & 62.5 & 28 & 58.3 & $\mathrm{P}=0.385$ \\
\hline
\end{tabular}

Table 3: comparing age and duration of diabetes in two groups 


\begin{tabular}{|l|l|l|l|}
\hline Variables & Intervention & Control & \multirow{2}{*}{ Sig. } \\
\cline { 2 - 4 } & Mean \pm SD & Mean \pm SD & \\
\hline Age & $55.2 \pm 1.23$ & $57.66 \pm 1.09$ & $\begin{array}{l}\mathrm{T}=0.508 \\
\mathrm{P}=0.616\end{array}$ \\
\hline time period of being diagnosed with diabetes & $6.62 \pm 1.10$ & $7.62 \pm 0.93$ & $\begin{array}{l}\mathrm{Z}=0.986 \\
\mathrm{P}=0.324\end{array}$ \\
\hline
\end{tabular}

Table 4: the normality results of quantitative variables

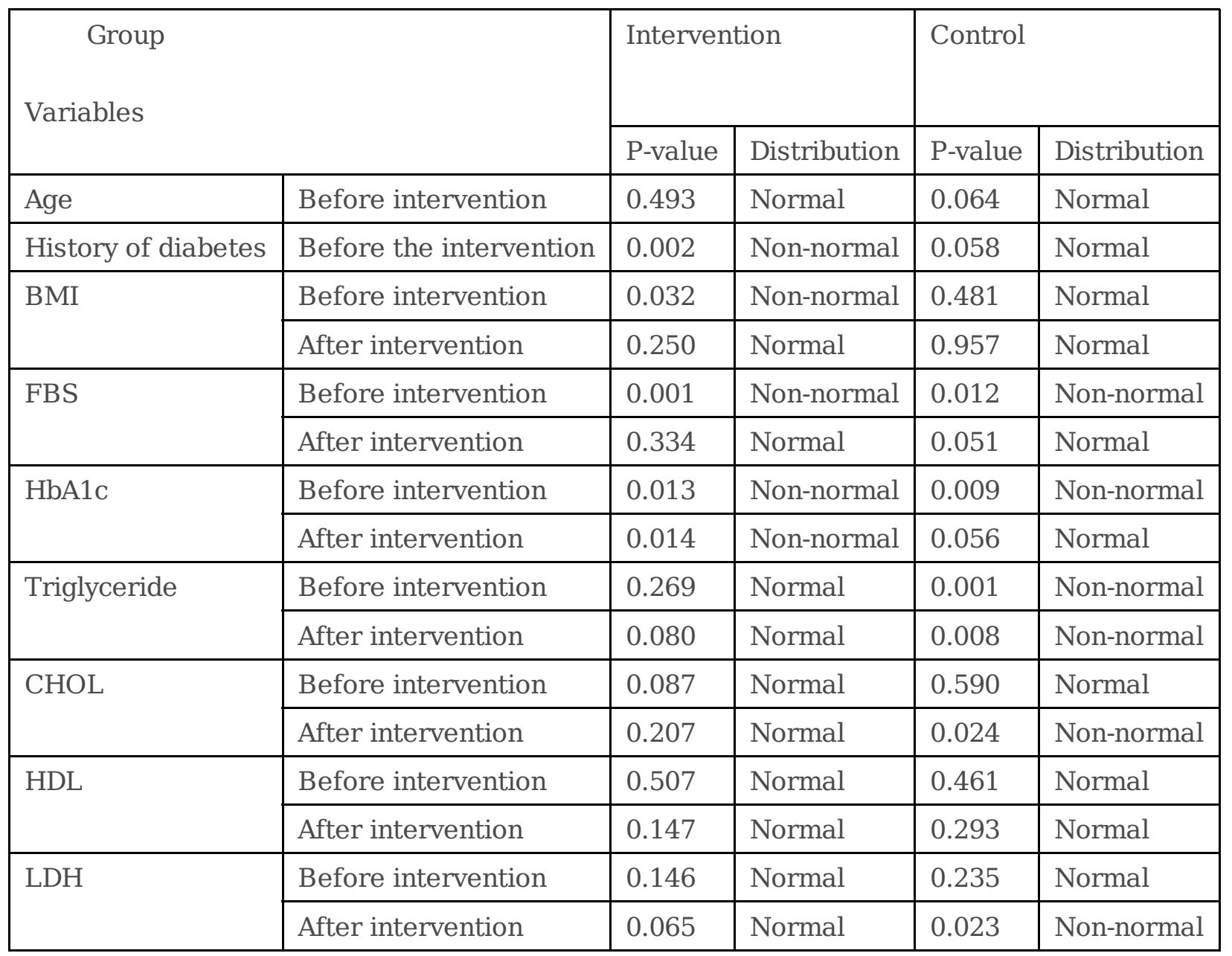

Table 5: comparing intervention and control groups in term of metabolic indexes before and after intervention 


\begin{tabular}{|c|c|c|c|}
\hline Variable & group & before & after \\
\hline \multirow[t]{2}{*}{ BMI (mean rank \& mean and SD) } & intervention & 25.63 & $27.73 \pm 4.23$ \\
\hline & control & 23.38 & $26.60 \pm 3.16$ \\
\hline \multicolumn{2}{|l|}{ Statistical tests } & $\begin{array}{l}P=0.578 \\
Z=-0.557\end{array}$ & $\begin{array}{l}\mathrm{P}=0.301 \\
\mathrm{t}=1.047\end{array}$ \\
\hline \multirow[t]{2}{*}{ FBS (mean rank \& mean and SD) } & intervention & 23.90 & $148.41 \pm 24.81$ \\
\hline & control & 25.10 & $176.29 \pm 40.94$ \\
\hline \multicolumn{2}{|l|}{ Statistical tests } & $\begin{array}{l}P=0.765 \\
Z=-0.299\end{array}$ & $\begin{array}{l}\mathrm{P}=0.006^{*} \\
\mathrm{t}=-2.852\end{array}$ \\
\hline \multirow[t]{2}{*}{ HbA1c (mean rank) } & intervention & 23.13 & 20.31 \\
\hline & control & 25.88 & 28.29 \\
\hline \multicolumn{2}{|l|}{ Statistical tests } & $\begin{array}{l}P=0.496 \\
Z=-0.681\end{array}$ & $\begin{array}{l}\mathrm{P}=0.038^{*} \\
\mathrm{Z}=-2.073\end{array}$ \\
\hline \multirow[t]{2}{*}{ TG (mean rank) } & intervention & 26.85 & 22.15 \\
\hline & control & 26.06 & 22.94 \\
\hline \multicolumn{2}{|l|}{ Statistical tests } & $\begin{array}{l}\mathrm{P}=0.244 \\
\mathrm{Z}=-1.165\end{array}$ & $\begin{array}{l}P=0.439 \\
Z=-0.773\end{array}$ \\
\hline \multirow[t]{2}{*}{ CHOL (mean and SD\& mean rank) } & intervention & $211.70 \pm 50.52$ & 25.02 \\
\hline & control & $194.08 \pm 57.01$ & 23.98 \\
\hline \multicolumn{2}{|l|}{ Statistical tests } & $\begin{array}{l}\mathrm{P}=0.263 \\
\mathrm{t}=1.133\end{array}$ & $\begin{array}{l}P=0.797 \\
Z=-0.258\end{array}$ \\
\hline \multirow[t]{2}{*}{ HDL (mean and SD\& mean rank) } & intervention & $35.41 \pm 7.58$ & 23.63 \\
\hline & control & $36 \pm 11.12$ & 25.38 \\
\hline \multicolumn{2}{|l|}{ Statistical tests } & $\begin{array}{l}\mathrm{P}=0.833 \\
\mathrm{t}=-0.212\end{array}$ & $\begin{array}{l}P=0.664 \\
Z=-0.434\end{array}$ \\
\hline \multirow[t]{2}{*}{ LDL (mean and SD\& mean rank) } & intervention & $106.16 \pm 29.77$ & 27.35 \\
\hline & control & $91.70 \pm 31.52$ & 21.65 \\
\hline \multicolumn{2}{|l|}{ Statistical tests } & $\begin{array}{l}\mathrm{P}=0.109 \\
\mathrm{t}=-1.633\end{array}$ & $\begin{array}{l}P=0.157 \\
Z=-1.414\end{array}$ \\
\hline
\end{tabular}

z Mann-Whithney t Independent t-test *significant

Table 6: comparing metabolic indexes before and after intervention in both groups 


\begin{tabular}{|c|c|c|c|}
\hline Variable & group & intervention & control \\
\hline \multirow[t]{2}{*}{ BMI (mean rank \& mean and SD) } & before & 25.62 & $26.97 \pm 2.87$ \\
\hline & after & 26.13 & $26.60 \pm 3.16$ \\
\hline \multicolumn{2}{|l|}{ Statistical tests } & $\begin{array}{l}* \mathrm{P}=0.031 \\
\mathrm{Z}=-2.153\end{array}$ & $\begin{array}{l}P=0.162 \\
t=1.443\end{array}$ \\
\hline \multirow[t]{2}{*}{ FBS (mean rank) } & before & 23.90 & 25.10 \\
\hline & after & 19.25 & 29.75 \\
\hline \multicolumn{2}{|l|}{ Statistical tests } & $\begin{array}{l}* \mathrm{P}=0.001 \\
\mathrm{Z}=-3.258\end{array}$ & $\begin{array}{l}P=0.424 \\
Z=-0.800\end{array}$ \\
\hline \multirow[t]{2}{*}{ HbA1c (mean rank) } & before & 23.13 & 25.88 \\
\hline & after & 20.31 & 28.69 \\
\hline \multicolumn{2}{|l|}{ Statistical tests } & $\begin{array}{l}* \mathrm{P}=0.003 \\
\mathrm{Z}=-2.930\end{array}$ & $\begin{array}{l}P=0.772 \\
Z=-0.289\end{array}$ \\
\hline \multirow[t]{2}{*}{ TG (mean rank) } & before & $205.79 \pm 76.81$ & 22.15 \\
\hline & after & $200.12 \pm 87.50$ & 22.94 \\
\hline \multicolumn{2}{|l|}{ Statistical tests } & $\begin{array}{l}\mathrm{P}=0.701 \\
\mathrm{Z}=0.388\end{array}$ & $\begin{array}{l}P=0.679 \\
Z=0.414\end{array}$ \\
\hline \multirow[t]{2}{*}{ CHOL (mean and SD\& mean rank) } & before & $211.70 \pm 50.52$ & 22.48 \\
\hline & after & $181.12 \pm 36.78$ & 23.98 \\
\hline \multicolumn{2}{|l|}{ Statistical tests } & $\begin{array}{l}* \mathrm{P}=0.001 \\
\mathrm{t}=4.231\end{array}$ & $\begin{array}{l}P=0.390 \\
Z=0.860\end{array}$ \\
\hline \multirow[t]{2}{*}{ HDL (mean and SD\& mean rank) } & before & $35.41 \pm 7.56$ & 24.60 \\
\hline & after & $36 \pm 11.12$ & 25.38 \\
\hline \multicolumn{2}{|l|}{ Statistical tests } & $\begin{array}{l}P=0.712 \\
t=0.373\end{array}$ & $\begin{array}{l}P=0.775 \\
Z=-0.286\end{array}$ \\
\hline \multirow[t]{2}{*}{ LDL (mean and SD\& mean rank) } & before & $106.16 \pm 29.77$ & 21.85 \\
\hline & after & $91.70 \pm 31.52$ & 21.65 \\
\hline \multicolumn{2}{|l|}{ Statistical tests } & $\begin{array}{l}* \mathrm{P}=0.031 \\
\mathrm{t}=2.282\end{array}$ & $\begin{array}{l}P=0.466 \\
Z=-0.729\end{array}$ \\
\hline
\end{tabular}

*significant

Figures 


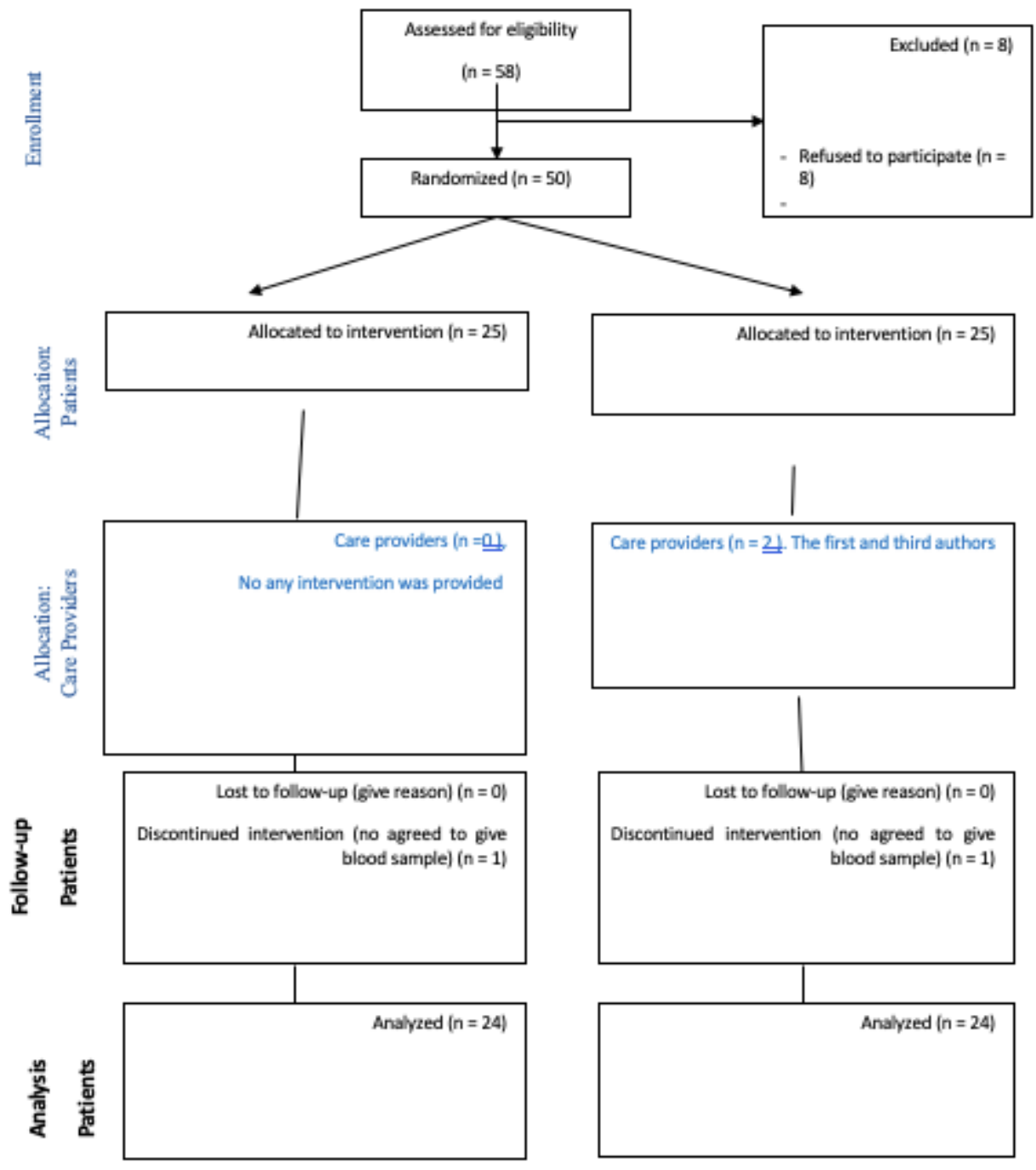

Figure 1

The Consort flow chart of the study 